\title{
Thermal and microwave synthesis of silica fume- based solid activator for the one-part geopolymerization of fly ash
}

Olga Andriana Panitsa ( $\nabla$ panitsaolg@mail.ntua.gr)

NTUA: Ethniko Metsobio Polytechneio https://orcid.org/0000-0003-4093-0280

Dimitrios Kioupis

NTUA: Ethniko Metsobio Polytechneio

Glikeria Kakali

NTUA: Ethniko Metsobio Polytechneio

\section{Research Article}

Keywords: Alkali activation, one-part geopolymer, just-add water, fly ash, solid activator, silica fume, microwave treatment

Posted Date: March 1st, 2022

DOl: https://doi.org/10.21203/rs.3.rs-1350468/v1

License: (영 This work is licensed under a Creative Commons Attribution 4.0 International License. Read Full License

Version of Record: A version of this preprint was published at Environmental Science and Pollution Research on April 6th, 2022. See the published version at https://doi.org/10.1007/s11356-022-20081-9. 


\section{Abstract}

This paper tests the development of a silica fume-based material, capable to be used as a solid activator for the one-part geopolymerization of fly ash. Through a simple procedure, a mixture of silica fume, an amorphous and silicon-rich by-product, sodium hydroxide and water, is converted, after a low temperature treatment, to a new powder product mainly containing sodium silicate $\left(\mathrm{Na}_{2} \mathrm{SiO}_{3}\right)$. Two different treatment methods are tested for the synthesis of the solid activator: heat and microwave treatment. Microwave processing is more sustainable and more efficient than thermal treatment, since purer products are produced with less energy consumption. The use of these low embodied energy products, as the only solid activator of fly ash, leads to geopolymers with comparable mechanical performance to those prepared with commercial products revealing their potential successful addition in the geopolymer market.

\section{Introduction}

Geopolymers are the most promising cement replacers to meet the need for a more environmentally friendly construction sector, that uses sustainable building materials (Zhang et al. 2020; Shehata et al. 2021). Traditional geopolymerization process is based on the activation of an aluminosilicate precursor using an alkaline sodium silicate solution (wasteglass) (Provis and Deventer 2014). More specifically, silica and alumina rich industrial wastes and by-products (e.g. fly ash and slags) (Zaharaki et al. 2016; Gnanadurai et al. 2021; Ren et al. 2021; Shahmansouri et al. 2021; Shrivas et al. 2022; Peng and Unluer 2022; Wu et al. 2022) are used as precursors, reducing the final geopolymer product's energy footprint (Kioupis et al. 2018b). Even so, despite the geopolymers' characteristics (high strength, resistance to acid and heat), this technology has not been widely applied, due to issues caused by the activation solution. This high alkaline solution has two main drawbacks: it is very corrosive and causes handling issues, and its production process is characterized by high energy consumption and cost (Alnahhal et al. 2021).

To overcome the first obstacle, the research community has focused, lately, on the development of solid activators, capable to substitute the alkaline solution (Luukkonen et al. 2018). More particularly, various reagents have been tested as single solid activators or as part of a mix of solid activators: $\mathrm{Na}_{2} \mathrm{CO}_{3}$ (Peng et al. 2015), $\mathrm{NaAlO}_{2}$ (Hajimohammadi et al. 2010), $\mathrm{CaSO}_{4}$ (García-Lodeiro et al. 2016), $\mathrm{Na}_{2} \mathrm{SO}_{4}$ (García-Lodeiro et al. 2016), $\mathrm{NaOH}$ (Peng et al. 2017), $\mathrm{KOH}$ (Koloušek et al. 2007) and sodium silicates with various moduli $\left(\mathrm{SiO}_{2} / \mathrm{Na}_{2} \mathrm{O}\right.$ molar ratio) (Nematollahi et al. 2015). The most efficient, based on the mechanical properties of the final geopolymers, was found to be anhydrous sodium metasilicate $\mathrm{Na}_{2} \mathrm{SiO}_{3}$ (Nematollahi et al. 2015; Panitsa et al. 2021; Wang et al. 2021).

However, alkali silicates have high embodied energy and high manufacturing cost as they need extreme conditions for their production (Fawer et al. 1999). There are several different sodium silicate production methods. Sodium carbonate, $\mathrm{Na}_{2} \mathrm{CO}_{3}$, and silica sand can be mixed and cured at $1000-1400{ }^{\circ} \mathrm{C}$ to produce sodium silicate, $\mathrm{Na}_{2} \mathrm{SiO}_{3}$. Then, water is added to create the solution (waterglass) (Lagaly et al. 2000). Sodium silicate can also be prepared directly by dissolving silica sand under pressure in a heated aqueous solution of sodium hydroxide, $\mathrm{NaOH}$ (Novotny et al. 1991). 
An alternative method of producing sodium silicate compounds, using solid wastes and by-products, has been proposed (Alnahhal et al. 2021). Susan A. Bernal et al. prepared an alkaline solution by mixing silica fume or rice husk ash with aqueous $\mathrm{NaOH}$, for the alkali activation of a metakaolin/slag binder mixture (Bernal et al. 2012). D. Kioupis et al. used waste glass to produce an alkaline solution for the geopolymerization of brick (Kioupis et al. 2020). Geopolymerization results showed the efficacy of those waste-based sodium silicate solutions. Moreover, Raffaele Vinaia and Marios Soutsos have prepared a sodium silicate product that can be used as a solid activator in an alkali activation process (Vinai and Soutsos 2019).

The purpose of this study is to produce a waste-based sodium silicate solid substance from silica fume, with lower production energy requirements and embodied energy. Consequently, this substance will be able to totally substitute the commercial reagents with the same chemical formula. Silica fume is a by-product of silicon metal or ferrosilicon alloys production process, with a high amorphous silicon dioxide content (>90\%). The synthesis process includes the mixing of silica fume, $\mathrm{NaOH}$ and water. The created slurry is thermally treated at $150^{\circ} \mathrm{C}$ to obtain a solid powder. Moreover, to simplify the production process and decrease the energy footprint of the waste based final product, the use of microwave treatment was tested as well. Lastly, this new product is tested as a solid activator, for the geopolymerization of Greek fly ash, to investigate its reactivity and geopolymerization potential.

\section{Materials And Methods}

Silica fume from Sikafume ${ }^{\circledR}-\mathrm{HR}\left(\mathrm{SiO}_{2}>90 \% \mathrm{w} / \mathrm{w}\right)$ and commercial sodium hydroxide (CAS No. 1310-73-2, $\mathrm{NaOH} \geq 98.0 \% \mathrm{w} / \mathrm{w}$ ) were used. Commercial sodium metasilicate - $\mathrm{Na}_{2} \mathrm{SiO}_{3}$ (CAS No. 6834-92-0) and sodium silicate $-\mathrm{Na}_{2} \mathrm{Si}_{2} \mathrm{O}_{5}$ (CAS No. 6834-92-0) were also used as solid activators for comparison reasons. Fly ash was collected from Megalopolis power plant in Greece.

Table 1

Fly ash chemical composition

\begin{tabular}{|llllllllllll|}
\hline $\mathrm{SiO}_{2}$ & $\mathrm{Al}_{2} \mathrm{O}_{3}$ & $\mathrm{Fe}_{2} \mathrm{O}_{3}$ & $\mathrm{CaO}$ & $\mathrm{MgO}$ & $\mathrm{K}_{2} \mathrm{O}$ & $\mathrm{Na}_{2} \mathrm{O}$ & $\mathrm{SO}_{3}$ & $\mathrm{TiO}_{2}$ & $\mathrm{P}_{2} \mathrm{O}_{5}$ & $\mathrm{MnO}$ & L.O.I. \\
\hline 40.60 & 20.58 & 3.33 & 11.61 & 1.19 & 0.72 & 0.23 & 0.90 & 0.79 & 0.26 & 0.06 & 16.70 \\
\hline
\end{tabular}

Its chemical composition was determined through X-ray fluorescence spectroscopy (XRF, Malvern Panalytical, Epsilon 1 Model) and is shown in Table 1. The raw materials' particle size distribution was determined through Malvern Mastersizer Micro (Fig. 1). Fly ash was previously ground to a mean particle size $\left(d_{50}\right)$ of approximately $20 \mu \mathrm{m}$, which is a typical fineness of fly ash when used in the construction industry.

Table 2. ID samples and the investigated parameters 


\begin{tabular}{llllll} 
Mix ID & $\begin{array}{l}\mathrm{SiO}_{2} / \mathrm{Na}_{2} \mathrm{O} \text { molar } \\
\text { ratio }\end{array}$ & $\begin{array}{l}\text { Treatment } \\
\text { method }\end{array}$ & $\begin{array}{l}\text { Temperature } \\
\left({ }^{\circ} \mathrm{C}\right)\end{array}$ & $\begin{array}{l}\text { Power } \\
\text { (Watt) }\end{array}$ & $\begin{array}{l}\text { Treatment } \\
\text { Duration }\end{array}$ \\
\hline 1SS_TT_330C_0.5h & 1 & Thermal & 330 & - & $0.5 \mathrm{~h}$ \\
\hline 1SS_TT_330C_1h & 1 & Thermal & 330 & - & $1 \mathrm{~h}$ \\
\hline 1SS_TT_330C_2h & 1 & Thermal & 330 & - & $2 \mathrm{~h}$ \\
\hline 1SS_TT_330C_3h & 1 & Thermal & 330 & - & $3 \mathrm{~h}$ \\
\hline 1SS_TT_150C_1h & 1 & Thermal & 150 & - & $1 \mathrm{~h}$ \\
\hline 1SS_TT_250C_1h & 1 & Thermal & 250 & - & $1 \mathrm{~h}$ \\
\hline 1SS_TT_450C_1h & 1 & Thermal & 450 & - & $1 \mathrm{~h}$ \\
\hline 2SS_TT_150C_1h & 2 & Thermal & 330 & - & $1 \mathrm{~h}$ \\
\hline 1SS_MT_L_12m & 1 & Microwave & - & 120 & $12 \mathrm{~min}$ \\
\hline 1SS_MT_M_12m & 1 & Microwave & - & 460 & $12 \mathrm{~min}$ \\
\hline 1SS_MT_H_12m & 1 & Microwave & - & 700 & $12 \mathrm{~min}$ \\
\hline 1SS_MT_M_2m & 1 & Microwave & - & 460 & $2 \mathrm{~min}$ \\
\hline 1SS_MT_M_20m & 1 & Microwave & - & 460 & $20 \mathrm{~min}$ \\
\hline 2SS_MT_M_2m & 2 & Microwave & - & 460 & $12 \mathrm{~min}$
\end{tabular}

Abbreviations: "1SS": $\mathrm{SiO}_{2} / \mathrm{Na}_{2} \mathrm{O}$ molar ratio equal to 1, "2SS": $\mathrm{SiO}_{2} / \mathrm{Na}_{2} \mathrm{O}$ molar ratio equal to 2, "TT": thermal treatment, "MT": microwave treatment, "150C-450C": treatment temperature, "2m-3h": treatment duration in minutes or hours, "L, M, H": microwave power (Low:120W, Medium:460W, High:700W)

For the synthesis of the silica fume-based activators (SFAs), specific amounts of silica fume, $\mathrm{NaOH}$ and water were mixed together to create a pulp. As for the amount of water that was added was the minimum needed to dilute completely the $\mathrm{NaOH}$ pearls. Then, the mixtures were treated appropriately, in order to obtain dry products in powder form.

An investigation of several treatment parameters was carried out to determine their effect on the SFAs and optimize their synthesis process (Table 2). More particularly, treatment duration ( $0.5 \mathrm{~h}, 1 \mathrm{~h}, 2 \mathrm{~h}$ and $3 \mathrm{~h}$ ), temperature $\left(150^{\circ} \mathrm{C}, 250^{\circ} \mathrm{C}, 330^{\circ} \mathrm{C}\right.$ and $450^{\circ} \mathrm{C}$ ) and $\mathrm{SiO}_{2} / \mathrm{Na}_{2} \mathrm{O}$ molar ratio ( 1 and 2) were the three tested parameters during thermal treatment. An alternative treatment method was investigated as well, using a microwave oven for household use. The tested parameters during the microwave treatment were the treatment duration ( $2 \mathrm{~min}, 12 \mathrm{~min}$ and $20 \mathrm{~min}$ ), the microwave power (120 W, $460 \mathrm{~W}$ and $700 \mathrm{~W}$ ) and the $\mathrm{SiO}_{2} / \mathrm{Na}_{2} \mathrm{O}$ molar ratio (1 and 2). In both treatment methods, minimum treatment duration was the least needed to get a dry product.

The solubility of SFAs was determined by dilution of $1 \mathrm{~g}$ in $150 \mathrm{~mL}$ of water for $1 \mathrm{~h}$ under stirring, followed by filtration and weighing of the solid residue. 
Table 3

Geopolymer mixtures prepared in this study [\% wt.]

\begin{tabular}{|c|c|c|c|c|c|c|c|c|c|}
\hline \multirow[t]{2}{*}{ Mix ID } & \multirow[t]{2}{*}{ FA } & \multicolumn{7}{|c|}{ Activator } & \multirow[t]{2}{*}{$\mathrm{H}_{2} \mathrm{O}$} \\
\hline & & sol & 1SS_COM & 2SS_COM & 3SS_COM & $1 S S$ & 2SS & NH & \\
\hline G2P & 60.4 & 14.8 & - & - & - & - & - & 9.8 & 14.9 \\
\hline G1P_1SS_COM ${ }^{24}$ & 61.3 & - & 15.3 & - & - & - & - & - & 23.4 \\
\hline G1P_2SS_COM ${ }^{24}$ & 63.1 & - & - & 11.6 & - & - & - & 5.2 & 20 \\
\hline G1P_1SS_TT_150C & 63.8 & - & - & - & - & 15.9 & - & - & 20.3 \\
\hline G1P_2SS_TT_150C & 59.3 & - & - & - & - & - & 10.9 & 4.9 & 24.9 \\
\hline G1P_1SS_MT_M & 64.0 & - & - & - & - & 16 & - & - & 20 \\
\hline G1P_2SS_MT_M & 57.6 & - & - & - & - & - & 10.6 & 4.7 & 27.1 \\
\hline \multicolumn{10}{|c|}{ 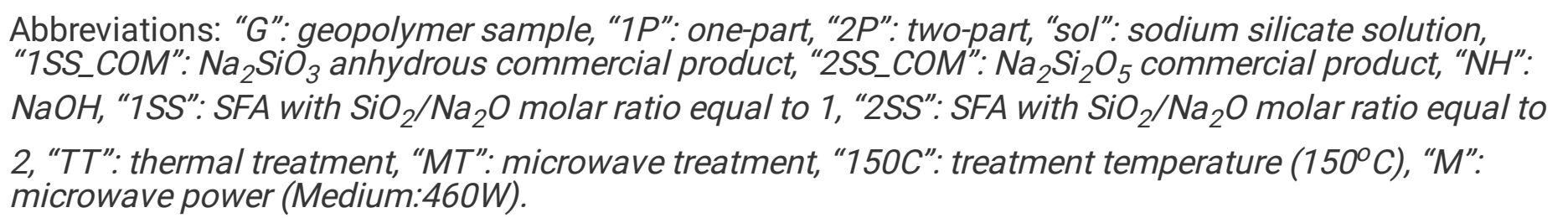 } \\
\hline
\end{tabular}

In order to examine the SFAs potential as solid activators in geopolymerization process, one-part fly-ash geopolymers were prepared (Table 3). Solid activators (commercial and prepared) were dry mixed with fly ash for 3 minutes in a mortar mixer (Controls 65-L0005). Then, water was added in order to reach the desired workability of the paste and to obtain homogenous slurry. At that moment, slurry was casted into cubic

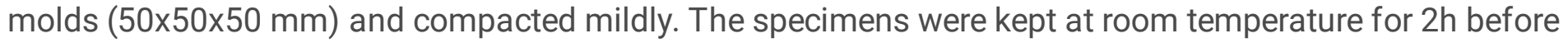
cured at $70{ }^{\circ} \mathrm{C}$ for $48 \mathrm{~h}$. Finally, compressive strength testing was carried out on the 7 th day after casting of the specimens, using a uniaxial testing press from Matest, E181N model, with load rate value $1.5 \mathrm{KN} / \mathrm{s}$, according to ASTM C109. The treatment duration for the thermally treated SFAs used for the geopolymers preparation reached $1 \mathrm{~h}$ and for the microwave treated $2 \mathrm{~min}$.

A two-part geopolymer (2P) was also prepared as a reference sample, using a sodium silicate solution as activator $\left(\mathrm{SiO}_{2}=27.6-28.4 \%\right.$ wt. and $\mathrm{Na}_{2} \mathrm{O}=8.5-8.8 \%$ wt. $)$. The $2 \mathrm{P}$ synthesis parameters were previously optimized and kept constant in all one-part geopolymers (1P). The method of optimization was reported elsewhere (Panagiotopoulou et al. 2015). The optimized synthesis parameters, for the geopolymerization of the fly ash used in this study are $\mathrm{Si} / \mathrm{Al}=2.18[\mathrm{a}]$ and $\mathrm{Na} / \mathrm{Al}=1[\mathrm{~b}]$. In case of the $2 \mathrm{SS}$ activators, further addition of $\mathrm{NaOH}$ is required in the raw mixture, in order to obtain the same synthesis parameters.

Raw materials and products were characterized appropriately by applying three analytical techniques. The mineralogical characterization was carried out by X-ray diffraction (XRD), using a Bruker D8 ADVANCE x-ray diffractometer employing CuKa radiation. The measuring conditions were: $2 \theta$ range $10-70^{\circ}$, step size 0.1 $\% \mathrm{sec}(0.02 \mathrm{sec}$ for Topas analysis) and the data were evaluated using Diffrac Eva v3.1 software. The evaluation of activators' crystallinity was performed through TOPAS software. Prior to the measurement, a known amount (9.9\% w/w) of zincate (commercial reagent, CAS No 1314-13-2) was added as a spike. FTIR 
measurements were conducted on a Fourier Transform IR Spectrophotometer (Jasco 4200 Type A). The FTIR spectra were obtained within a wavenumber range from 400 to $4000 \mathrm{~cm}^{-1}$ and resolution of $4 \mathrm{~cm}^{-1}$, using the $\mathrm{KBr}$ technique. Lastly, the final geopolymers were examined applying Scanning Electron Microscopy (SEM) on a SEM-EDAX/FEI Quanta 200 equipped with a low vacuum Secondary Electron (LFD) Detector.

[a] The overall amount of Si involved in the geopolymerization process expressed as the Si/Al molar ratio [b] The alkalinity of the activators expressed as sodium to aluminium molar ratio $\mathrm{Na} / \mathrm{Al}$.

\section{Results And Discussion}

\section{Synthesis and characterization of the SFAs}

Figures 2 and 3 present the XRD patterns of the SFAs products with $\mathrm{SiO}_{2} / \mathrm{Na}_{2} \mathrm{O}$ ratio equal to 1 and 2 , respectively, after thermal and microwave treatment.

The silica fume pattern presents a broad hump around $21^{\circ} 2 \theta$ which is indicative of amorphous silicon oxide. In the case of products with molar ratio $\mathrm{SiO}_{2} / \mathrm{Na}_{2} \mathrm{O}=1$, rregardless of the treatment method or the applied parameters, silica fume was converted successfully to the crystalline phase of $\mathrm{Na}_{2} \mathrm{SiO}_{3}$, similarly to the commercial product 1SS_COM (Fig. 2a, 3a). In the case of thermally treated samples, traces of natrite, $\mathrm{Na}_{2} \mathrm{CO}_{3}$, and thermonatrite, $\mathrm{Na}_{2} \mathrm{CO}_{3} \cdot \mathrm{H}_{2} \mathrm{O}(<4 \% \mathrm{w} / \mathrm{w})$ are also present in the final products, because of the sodium hydroxide carbonation. However, carbonation did not occur in the microwave treated samples since no carbonates were detected in their XRD patterns. This is most probably due to the limited air-exposure of these samples as the treatment lasts less than $20 \mathrm{~min}$.

Moreover, SFAs with ratio $\mathrm{SiO}_{2} / \mathrm{Na}_{2} \mathrm{O}=2$ (Fig. 2b, 3b) show high amorphousness like the commercial product 2SS_COM. A displacement of the amorphous peak of silica fume in higher degrees $\left(29^{\circ}\right)$ is observed for both products prepared with $\mathrm{SiO}_{2} / \mathrm{Na}_{2} \mathrm{O}=2$ (2SS_TT_330C_1h and 2SS_MT_M_2m). This is a sign of atoms' reorganization and the formation of new amorphous phases. Table 4 presents the $\% \mathrm{w} / \mathrm{w}$ mineral composition of the solid activators as it was obtained from the quantitative XRD analysis along with their solubility in water. 
Table 4

Mineral composition and water solubility of the solid activators.

\begin{tabular}{|c|c|c|c|c|c|}
\hline Sample ID & $\begin{array}{l}\mathrm{Na}_{2} \mathrm{SiO}_{3} \\
(\%)\end{array}$ & $\begin{array}{l}\mathrm{Na}_{2} \mathrm{CO}_{3} \\
(\%)\end{array}$ & $\begin{array}{l}\mathrm{Na}_{2} \mathrm{CO}_{3} * \mathrm{H}_{2} \mathrm{O} \\
(\%)\end{array}$ & $\begin{array}{l}\text { Amorphous } \\
\text { (\%) }\end{array}$ & $\begin{array}{l}\text { Normalized solubility } \\
\text { (\%) }\end{array}$ \\
\hline \multicolumn{6}{|l|}{ Commercial } \\
\hline 1SS_COM & 50.90 & - & - & 49.10 & 99.10 \\
\hline 2SS_COM & 0.00 & - & - & 100.00 & 99.20 \\
\hline \multicolumn{6}{|l|}{ Thermal Treated } \\
\hline $\begin{array}{l}\text { 1SS_TT_ } \\
\text { 330C_0.5h }\end{array}$ & 66.71 & 3.65 & 1.14 & 28.49 & 98.00 \\
\hline 1SS_TT_330C_1h & 77.35 & 1.91 & 1.75 & 18.98 & 95.81 \\
\hline 1SS_TT_330C_2h & 71.04 & 2.67 & 0.43 & 25.85 & 96.09 \\
\hline 1SS_TT_330C_3h & 72.29 & & 0.16 & 25.98 & 96.73 \\
\hline 1SS_TT_150C_1h & 58.97 & 2.24 & 0.64 & 38.15 & 97.22 \\
\hline 1SS_TT_250C_1h & 69.48 & 3.20 & 0.43 & 26.89 & 96.89 \\
\hline 1SS_TT_450C_1h & 80.91 & 1.91 & 0.01 & 17.17 & 96.58 \\
\hline 2SS_TT_330C_1h & 1.76 & 0.00 & 0.00 & 98.24 & 76.40 \\
\hline \multicolumn{6}{|l|}{ Microwave treated } \\
\hline 1SS_MT_M_2min & 56.10 & - & - & 43.90 & 97.63 \\
\hline 1SS_MT_H_2min & 52.60 & - & - & 43.00 & 98.83 \\
\hline 1SS_MT_L_12min & 50.30 & - & - & 49.70 & 97.92 \\
\hline 1SS_MT_M_12min & 69.90 & - & - & 30.10 & 97.32 \\
\hline 1SS_MT_H_12min & 66.70 & - & - & 33.30 & 97.76 \\
\hline 1SS_MT_M_20min & 64.30 & - & - & 35.70 & 98.37 \\
\hline 2SS_MT_M_2min & 0.00 & - & - & 100.00 & 95.52 \\
\hline SF & - & - & - & 100.00 & 7.93 \\
\hline
\end{tabular}

Concerning the SFAs with molar ratio $\mathrm{SiO}_{2} / \mathrm{Na}_{2} \mathrm{O}=1$, it is obvious that products with higher crystallinity, compared with the commercial ones, were prepared. In addition, heat treatment is more efficient for the preparation of high crystalline samples (62-81 \%), compared with the microwave treatment (50-70 \%). Sodium silicate $\mathrm{Na}_{2} \mathrm{SiO}_{3}$ is the main crystalline phase, and in some cases the only one, that characterizes the SFAs composition. 
The increase of the temperature from 150 to $450{ }^{\circ} \mathrm{C}$, increases the content of crystalline $\mathrm{Na}_{2} \mathrm{SiO}_{3}$ by $27 \%$, in the thermally treated samples (Fig. 4a). In a similar manner, the crystalline content of $\mathrm{Na}_{2} \mathrm{SiO}_{3}$ in the microwave treated samples was enhcaced by $28 \%$ when the power of the microwave source altered from 120 to 460 W (Fig. 4b). In both cases, further increase of temperature or power did not yield any remarkable change of the crystalline content.

Treatment duration effect on $\mathrm{Na}_{2} \mathrm{SiO}_{3}$ crystalline content of SFAs was not so pronounced in relation to the temperature or power effect. In particular, a treatment duration increase, from 0.5 to $1 \mathrm{~h}$, in thermally treated samples led to a $14 \%$ increase of the crystalline $\mathrm{Na}_{2} \mathrm{SiO}_{3}$ (Fig. 4a). Similarly, an alteration of treatment duration, from 2 to $12 \mathrm{~min}$, in microwave treated samples led to a $20 \%$ increase in the crystalline content (Fig. 4b). Higher treatment duration, for both treatment methods, did not favor higher crystalline contents.

Concerning the effect of $\mathrm{SiO}_{2} / \mathrm{Na}_{2} \mathrm{O}$ molar ratio, products with $\mathrm{SiO}_{2} / \mathrm{Na}_{2} \mathrm{O}=1$ obtained a high crystalline content (>50\%) while those prepared with $\mathrm{SiO}_{2} / \mathrm{Na}_{2} \mathrm{O}=2$ are almost totally amorphous, following the structure of the commercial sodium silicates (1SS_COM and 2SS_COM).

Table 4, also presents the normalized solubility of the activators, calculated by excluding the carbonates' content. Results showed that commercial sodium silicates 1SS_COM and 2SS_COM are totally soluble in water. Silica fume, the raw material of the SFAs, is almost entirely insoluble in water, since it contains more than $90 \% \mathrm{SiO}_{2}(7.9 \%)$. Moreover, all SFAs with molar ratio $\mathrm{SiO}_{2} / \mathrm{Na}_{2} \mathrm{O}=1$, regardless the way they have been treated, are highly soluble in water (>95\%), similarly to the commercial product 1SS_COM, indicating that their amorphous phase consists of highly soluble compounds and, of course, the successful conversion of silica fume to new products. As concerns SFAs with molar ratio $\mathrm{SiO}_{2} / \mathrm{Na}_{2} \mathrm{O}=2$, the 2SS_TT_330C_1h sample exhibited a lower water solubility $(76.4 \%)$, indicating lower conversion yield. On the contrary, the sample 2SS_MT_M_2min showed a high solubility, close to $95 \%$, which may be attributed to higher conversion of silica to soluble silicate compounds. 
Table 5

FTIR band assignments (Brooker and Bates 1971; de Man and van Santen 1992; Ratcliffe and Irish 2002; Guo et al. 2010; Rashid et al. 2012; Kioupis et al. 2018a; Zanoletti et al. 2018; Ryu and Lee 2018)

\begin{tabular}{|c|c|}
\hline Frequencies $\left(\mathrm{cm}^{-1}\right)$ & Assignments \\
\hline 1630 & - $\mathrm{OH}$ bending vibrations $\left(\mathrm{H}_{2} \mathrm{O}\right)$ \\
\hline 1450 & O-C-O stretching vibrations \\
\hline \multicolumn{2}{|l|}{ Silica Fume } \\
\hline 1100 & $\mathrm{Si}-0-\mathrm{Si}$ asymmetric stretching vibrations \\
\hline 800 & $\begin{array}{l}\text { Si-O-Si symmetric stretching vibrations } \\
\text { (inter-tetrahedral Si-O-Si) }\end{array}$ \\
\hline 475 & $\mathrm{O}-\mathrm{Si}-\mathrm{O}$ bending vibrations \\
\hline \multicolumn{2}{|l|}{$1 \mathrm{SS}$} \\
\hline 1035 & $\mathrm{Si}-\mathrm{O}-\mathrm{Na}$ asymmetric stretching vibrations \\
\hline 970 & $\mathrm{Si}-0-\mathrm{Si}$ asymmetric stretching vibrations \\
\hline 880 & $\mathrm{Si}-\mathrm{O}-\mathrm{Na}$ symmetric stretching vibrations \\
\hline 710 & Si-0-Si symmetric stretching vibration \\
\hline 590 & in-plane $\mathrm{Si}-\mathrm{O}-\mathrm{Si}$ stretching mode coupled with \\
\hline 520 & O-Si-O and $\mathrm{Si}-0-\mathrm{Si}$ bending modes \\
\hline \multicolumn{2}{|l|}{$2 S S$} \\
\hline 1005 & $\mathrm{Si}-\mathrm{O}-\mathrm{Na}$ asymmetric stretching vibrations \\
\hline 880 & $\mathrm{Si}-0-\mathrm{Na}$ symmetric stretching vibrations \\
\hline 750 & O-Si-O stretching \\
\hline
\end{tabular}

Figure 5 a presents the FTIR spectra of the SFAs $\left(\mathrm{SiO}_{2} / \mathrm{Na}_{2} \mathrm{O}=1\right)$ prepared in this study. For comparison, the spectrum of the commercial sodium silicate (1SS_COM) as well as that of silica fume are presented in the same figure. Silica fume exhibits the typical vibrations of Si-O bonds. In particular, the absorption peaks at 1100 and $804 \mathrm{~cm}^{-1}$ are assigned to asymmetric and symmetric stretching vibrations of $\mathrm{Si}-\mathrm{O}-\mathrm{Si}$ bonds while that at $470 \mathrm{~cm}^{-1}$ is attributed to the bending vibrations of $\mathrm{O}-\mathrm{Si}-\mathrm{O}$ bonds. The band at $1630 \mathrm{~cm}^{-1}$ is related to the $-\mathrm{OH}$ bending vibrations and it indicates the existence of absorbed water. Concerning the 1SS_COM, the absorption peaks at 1036, 967, 885, 711, 590 and $515 \mathrm{~cm}^{-1}$ are attributed to varied IR vibrations of Si-O-T (T: Si or Na) and O-Si-O bonds on the structure of sodium silicates (Table 5). Furthermore, the band at $1450 \mathrm{~cm}^{-1}$ is assigned to the vibrations of carbonate ions and it is linked to the presence of sodium carbonate phase. It is obvious that irrespective the processing conditions, the reactants have successfully been transformed to sodium silicates. In particular, all the SFAs exhibit identical infrared spectra 
to that of the commercial product (Fig. 5). Furthermore, the characteristic broad peak of silica fume is not detected in the spectra of the activators, indicating the total conversion of silica fume to sodium silicates. The formation of the sodium silicate structure is majorly indicated by the shift of the $\mathrm{Si}-\mathrm{O}-\mathrm{Si}$ band at $1100 \mathrm{~cm}^{-1}$ to lower wavenumbers through the enrichment of $\mathrm{Si}-\mathrm{O}-\mathrm{T}$ bonds by $\mathrm{Na}$; "trident" absorption at 1040,970 and $880 \mathrm{~cm}^{-1}$. These results are in accordance with solubility rates of 1SSs (Table 4).

Figure $5 b$ presents the FTIR spectra of the $2 \mathrm{SS}$ activators $\left(\mathrm{SiO}_{2} / \mathrm{Na}_{2} \mathrm{O}=2\right)$, prepared in this study, along with the spectra of the commercial sodium silicate (2SS_COM) and silica fume. The 2SS_COM exhibits absorption peaks at 1005 and $880 \mathrm{~cm}^{-1}$ which are assigned to the asymmetric and symmetric stretching vibrations of SiO-Na bonds, respectively (Table 5). In addition, the band at $755 \mathrm{~cm}^{-1}$ could be linked to the stretching of $\mathrm{O}-$ $\mathrm{Si}-\mathrm{O}$ bonds. The spectrum of 2SS_COM is relatively featureless revealing the amorphous nature of this material, in accordance with the XRD analysis. As in the case of $1 \mathrm{SS}$ _COM, the band at $1450 \mathrm{~cm}^{-1}$ is related to the presence of sodium carbonate phases.

The spectra of the prepared 2SSs show clear differences in relation to that of the commercial product (2SS_COM). The thermally treated product (2SS_TT_150C_1h) exhibits a displacement of the wide absorption peak $\left(1000 \mathrm{~cm}^{-1}\right)$ to higher wavenumbers $\left(1050 \mathrm{~cm}^{-1}\right)$ while the band at $880 \mathrm{~cm}^{-1}$ is almost undetectable. This observation indicates the partial transformation of the silica fume to silicate compounds since a lower portion of $\mathrm{Si}-\mathrm{O}-\mathrm{Na}$ bonds have been formed in the final product. This speculation is in good accordance with the solubility of the products since 2SS_TT_150C_1 h sample shows a reduced solubility in water indicating that unreacted silica is still present in the product. The spectrum of the microwave treated sample (2SS_MT_M_2m) is quite similar with the spectrum of the thermally treated sample.

\section{Synthesis and characterization of geopolymers}

In order to evaluate the potential of the prepared samples, they were applied as activators for the geopolymerization of fly ash.

Its chemical composition was determined through X-ray fluorescence spectroscopy (XRF, Malvern Panalytical, Epsilon $1 \mathrm{Model}$ ) and is shown in Table 1. The raw materials' particle size distribution was determined through Malvern Mastersizer Micro (Fig. 1). Fly ash was previously ground to a mean particle size $\left(d_{50}\right)$ of approximately $20 \mu \mathrm{m}$, which is a typical fineness of fly ash when used in the construction industry.

The SFAs were selected in terms of the lowest energy consumption during their preparation. Therefore, the xSS_TT_150C_1h and xSS_MT_M_2m samples $\left(x=\mathrm{SiO}_{2} / \mathrm{Na}_{2} \mathrm{O}=1\right.$ or 2$)$ were used for the synthesis of geopolymers (Table 4). For comparison reasons, one and two-part geopolymers were also prepared, using the commercial products. It is worth-mentioning that the SFAs required quantities were calculated according to the assumption that they are totally consisted of sodium silicate phases.

An initial evaluation step of the successful production of building materials concerns the mechanical properties' measurement. In Figure 6, the uniaxial compressive strength of the prepared geopolymers is presented (average of three specimens). The geopolymer synthesis through the traditional liquid activator (G2P) achieves a compressive strength of $62.3 \mathrm{MPa}$. The replacement of the activation solution with 
commercial solid activators was successful, as expected ${ }^{10}$, since products with identical mechanical strength were obtained irrespectively of the $\mathrm{SiO}_{2} / \mathrm{Na}_{2} \mathrm{O}$ ratio of the activator (Fig. 6). The further replacement of the solid commercial activators by the SFAs showed promising results. More particularly, the geopolymers incorporating the 1SS_TT_150C or 1SS_MT_M_2m activators achieved the 90 to $95 \%$ of the compressive strength of the reference synthesis (G2P). The fact that the thermally treated activator achieves slightly lower mechanical strengths can be attributed to the presence of carbonate phases which lowers the reactivity of the material.

Concerning the geopolymer synthesis with 2SSs activators, the prepared geopolymers exhibit remarkably lower compressive strength in comparison to the G2P. Both G1P_2SS_TT_150C and G1P_2SS_MT_M_2m have much lower compressive strength than geopolymers with the commercial activators. These results are in accordance with the characterization analysis (solubility studies and FTIR) of these SFAs showing that silica haw ton totally transformed in sodium silicate compounds.

Figure 7 presents backscattered images of the geopolymers and EDS analysis of selected points. The geopolymers present the typical microstructure of fly ash based geopolymers, exhibiting a heterogenous structure consisting of a dense matrix and unreacted fly ash material. In particular, the fly ash cenospheres are partially or totally dissolved, depending on the progress of geopolymerization reaction.

Comparing the geopolymer materials, it can be seen that the products prepared with SFAs of $\mathrm{SiO}_{2} / \mathrm{Na}_{2} \mathrm{O}=1$, G1P_1SS_TT_150C (Fig. 7b) and G1P_1SS_MT_M (Fig. 7c), exhibit similar microstructure with that prepared with the commercial activator (G1P_1SS_COM, Fig. 7a). Furthermore, the stoichiometry of the geopolymer matrix obtained by EDS analysis is almost identical for the aforementioned samples and close to Si:Al:Na 21:10:9.

The G1P_2SS_COM (Fig. 7d) sample presents comparable microstructure to G1P_1SS_COM (Fig 7a) while the prepared aluminosilicate gel contains a slightly higher amount of sodium (Si:Al:Na 20:9:11). The sample prepared with thermally treated SFA (Fig. 7 e and f) shows a completely different morphology. The structure seems to be porous containing hollows of high diameter $(>200 \mu \mathrm{m})$ while it lacks cohesiveness revealing that a low portion of aluminosilicate gel has been formed. This observation confirms the findings of the alkali silicates preparation experiments that showed an extremely low conversion yield of silica fume to silicates when $\mathrm{SiO}_{2} / \mathrm{Na}_{2} \mathrm{O}$ equaled to 2 . The sample's stoichiometry by EDS analysis was calculated to Si:Al:Na 8:3:26 indicating that the unreacted sodium of waste-based activator have covered superficially the fly ash material.

\section{Conclusion}

This study concerns the synthesis of silica fume-based solid activators for fly ash geopolymerization. To reduce the energy requirement and simplify the synthesis procedure, microwave treatment was also applied, in addition to thermal treatment. Their potential of the activators was evaluated on the basis of the compressive strength of the relative geopolymers.

Results showed that: 
- Silica fume was successfully converted to a solid activator, rich in sodium silicate $\mathrm{Na}_{2} \mathrm{SiO}_{3}$, capable to solo-activate the aluminosilicate raw material. Prepared geopolymers showed the same mechanical strength to the reference ones that reached $60 \mathrm{MPa}$.

- Solid activators based on silica fume were obtained through a simple process where silica fume was mixed with $\mathrm{NaOH}$ and water to create a pulp. The pulp was then treated appropriately (thermal/ microwave treatment) to deliver a new powder product.

- Microwave processing is more sustainable and more efficient than thermal treatment, since purer products are produced with less energy consumption.

- XRD and FTIR results revealed the conversion of silica fume to a new product with a high sodium silicate content ( $>50 \%$ ). More particularly, solid activators with a molar ratio $\mathrm{SiO}_{2} / \mathrm{Na}_{2} \mathrm{O}=1$ are highly watersoluble materials (>95\%) and reactive enough to participate successfully in the geopolymerization process.

\section{Declarations}

\section{Ethical Approval and consent to participate}

Not Applicable

\section{Consent for publication}

Not Applicable

\section{Availability of data and materials}

The datasets used and/or analysed during the current study are available from the corresponding author on reasonable request.

\section{Competing interests}

The authors declare that they have no known competing financial interests or personal relationships that could have appeared to influence the work reported in this paper.

\section{Funding}

"This research is carried out / funded in the context of the project "Development of solid activators mixtures for fly ash geopolymerization" (MIS 50 5049183) under the call for proposals "Researchers' support with an emphasis on young researchers-2nd Cycle". The project is co-financed by Greece and the European Union (European Social Fund- ESF) by the Operational Programme Human Resources Development, Education and Lifelong Learning 2014-2020."

\section{Author Contributions}

All authors contributed to the study conception and design. Material preparation, data collection and analysis were performed by Olga Andriana Panitsa and Dimitrios Kioupis. The first draft of the manuscript was written 
by Olga Andriana Panitsa, Dimitrios Kioupis and all authors commented on previous versions of the manuscript. Prof. Glikeria Kakali supervised the research work, reviewed and edited the manuscript. All authors read and approved the final manuscript.

\section{Acknowledgements}

Not applicable

\section{References}

1. Alnahhal MF, Kim T, Hajimohammadi A (2021) Waste-derived activators for alkali-activated materials: A review. Cem Concr Compos 118:103980. https://doi.org/10.1016/j.cemconcomp.2021.103980

2. Bernal SA, Rodríguez ED, de Mejia R et al (2012) Activation of Metakaolin/Slag Blends Using Alkaline Solutions Based on Chemically Modified Silica Fume and Rice Husk Ash. Waste Biomass Valorization 3:99-108. https://doi.org/10.1007/s12649-011-9093-3

3. Brooker MH, Bates JB (1971) Raman and Infrared Spectral Studies of Anhydrous Li2CO3 and Na2CO3. J Chem Phys 54:4788-4796. https://doi.org/10.1063/1.1674754

4. de Man AJM, van Santen RA (1992) The relation between zeolite framework structure and vibrational spectra. Zeolites 12:269-279. https://doi.org/10.1016/S0144-2449(05)80295-7

5. Fawer M, Concannon M, Rieber W (1999) Life cycle inventories for the production of sodium silicates. Int J Life Cycle Assess 4:207. https://doi.org/10.1007/BF02979498

6. García-Lodeiro I, Carcelen-Taboada V, Fernández-Jiménez A, Palomo A (2016) Manufacture of hybrid cements with fly ash and bottom ash from a municipal solid waste incinerator. Constr Build Mater 105:218-226. https://doi.org/10.1016/j.conbuildmat.2015.12.079

7. Gnanadurai LT, Renganathan NT, Selvaraj CG (2021) Synthesis and characterization of synthetic sand by geopolymerization of industrial wastes (fly ash and GGBS) replacing the natural river sand. Environ Sci Pollut Res 28:56294-56304. https://doi.org/10.1007/s11356-021-14223-8

8. Guo F, Peng Z-G, Dai J-Y, Xiu Z-L (2010) Calcined sodium silicate as solid base catalyst for biodiesel production. Fuel Process Technol 91:322-328. https://doi.org/10.1016/j.fuproc.2009.11.003

9. Hajimohammadi A, Provis JL, van Deventer JSJ (2010) Effect of Alumina Release Rate on the Mechanism of Geopolymer Gel Formation. Chem Mater 22:5199-5208. https://doi.org/10.1021/cm101151n

10. Kioupis D, Kavakakis C, Tsivilis S, Kakali G (2018a) Synthesis and Characterization of Porous Fly AshBased Geopolymers Using Si. https://doi.org/10.1155/2018/1942898. as Foaming Agent

11. Kioupis D, Skaropoulou A, Tsivilis S, Kakali G (2020) Valorization of Brick and Glass CDWs for the Development of Geopolymers Containing More Than 80\% of Wastes. Minerals 10:672. https://doi.org/10.3390/min10080672

12. Kioupis D, Tsivilis S, Kakali G (2018b) Development of green building materials through alkali activation of industrial wastes and by-products. Mater Today Proc 5:27329-27336.

https://doi.org/10.1016/j.matpr.2018.09.048

Page 13/20 
13. Koloušek D, Brus J, Urbanova M et al (2007) Preparation, structure and hydrothermal stability of alternative (sodium silicate-free) geopolymers. J Mater Sci 42:9267-9275. https://doi.org/10.1007/s10853-007-1910-5

14. Lagaly G, Tufar W, Minihan A, Lovell A (2000) Silicates. In: Wiley -VCHV, GmbH, Co KGaA (eds) Ullmann's Encyclopedia of Industrial Chemistry. Wiley-VCH Verlag GmbH \& Co. KGaA, Weinheim, Germany, p a23661

15. Luukkonen T, Abdollahnejad Z, Yliniemi J et al (2018) One-part alkali-activated materials: A review. Cem Concr Res 103:21-34. https://doi.org/10.1016/j.cemconres.2017.10.001

16. Nematollahi B, Sanjayan J, Shaikh FUA (2015) Synthesis of heat and ambient cured one-part geopolymer mixes with different grades of sodium silicate. Ceram Int 41:5696-5704. https://doi.org/10.1016/j.ceramint.2014.12.154

17. Novotny R, Hoff A, Schuertz J (1991)Process for hydrothermal production of sodium silicate solutions

18. Panagiotopoulou C, Tsivilis S, Kakali G (2015) Application of the Taguchi approach for the composition optimization of alkali activated fly ash binders. Constr Build Mater 91:17-22. https://doi.org/10.1016/j.conbuildmat.2015.05.005

19. Panitsa O, Kioupis D, Kakali G (2021) One-Part Geopolymer Synthesis of Greek Fly Ash. Key Eng Mater 894:135-142

20. Peng MX, Wang ZH, Shen SH et al (2017) Alkali fusion of bentonite to synthesize one-part geopolymeric cements cured at elevated temperature by comparison with two-part ones. Constr Build Mater C 103112. https://doi.org/10.1016/j.conbuildmat.2016.11.010

21. Peng MX, Wang ZH, Shen SH, Xiao QG (2015) Synthesis, characterization and mechanisms of one-part geopolymeric cement by calcining low-quality kaolin with alkali. Mater Struct 3:699-708. https://doi.org/10.1617/s11527-014-0350-3

22. Peng Y, Unluer $C$ (2022) Analyzing the mechanical performance of fly ash-based geopolymer concrete with different machine learning techniques. Constr Build Mater 316:125785. https://doi.org/10.1016/j.conbuildmat.2021.125785

23. Provis J, van Deventer J (eds) (2014) Alkali Activated Materials: State-of-the-Art Report, RILEM TC 224AAM. Springer Netherlands

24. Rashid I, Omari MHA, Leharne SA et al (2012) Starch gelatinization using sodium silicate: FTIR, DSC, XRPD, and NMR studies. Starch - Stärke 64:713-728. https://doi.org/10.1002/star.201100190

25. Ratcliffe $\mathrm{Cl}$, Irish DE (2002) Vibrational spectral studies of solutions at elevated temperatures and pressures. 5. Raman studies of liquid water up to 300.degree.C. In: ACS Publ. https://pubs.acs.org/doi/pdf/10.1021/j100222a013. Accessed 11 Sep 2021

26. Ren B, Zhao Y, Bai H et al (2021) Eco-friendly geopolymer prepared from solid wastes: A critical review. Chemosphere 267:128900. https://doi.org/10.1016/j.chemosphere.2020.128900

27. Ryu YB, Lee MS (2018) Infrared Spectra and Thermal Properties of Sodium Silicate Solutions. Korean J Met Mater 56:72-78

28. Shahmansouri AA, Nematzadeh M, Behnood A (2021) Mechanical properties of GGBFS-based geopolymer concrete incorporating natural zeolite and silica fume with an optimum design using 
response surface method. J Build Eng 36:102138. https://doi.org/10.1016/j.jobe.2020.102138

29. Shehata N, Sayed ET, Abdelkareem MA (2021) Recent progress in environmentally friendly geopolymers: A review. Sci Total Environ 762:143166. https://doi.org/10.1016/j.scitotenv.2020.143166

30. Shrivas R, Paramkusam BR, Dwivedi SB (2022) Strength and durability performance of geopolymer binder of ambient cured alkali-activated MSW rejected waste and GGBFS mixes. Environ Sci Pollut Res. https://doi.org/10.1007/s11356-021-17547-7

31. Vinai R, Soutsos M (2019) Production of sodium silicate powder from waste glass cullet for alkali activation of alternative binders. Cem Concr Res 116:45-56.

https://doi.org/10.1016/j.cemconres.2018.11.008

32. Wang Y-S, Alrefaei Y, Dai J-G (2021) Roles of hybrid activators in improving the early-age properties of one-part geopolymer pastes. Constr Build Mater 306:124880.

https://doi.org/10.1016/j.conbuildmat.2021.124880

33. Wu B, Ma X, Deng H et al (2022) An efficient approach for mitigation of efflorescence in fly ash-based geopolymer mortars under high-low humidity cycles. Constr Build Mater 317:126159. https://doi.org/10.1016/j.conbuildmat.2021.126159

34. Zaharaki D, Galetakis M, Komnitsas K (2016) Valorization of construction and demolition (C\&D) and industrial wastes through alkali activation. Constr Build Mater 121:686-693. https://doi.org/10.1016/j.conbuildmat.2016.06.051

35. Zanoletti A, Vassura I, Venturini E et al (2018) A New Porous Hybrid Material Derived From Silica Fume and Alginate for Sustainable Pollutants Reduction. Front Chem 6:60. https://doi.org/10.3389/fchem.2018.00060

36. Zhang P, Wang K, Li Q et al (2020) Fabrication and engineering properties of concretes based on geopolymers/alkali-activated binders - A review. J Clean Prod 258:120896. https://doi.org/10.1016/j.jclepro.2020.120896

\section{Figures}




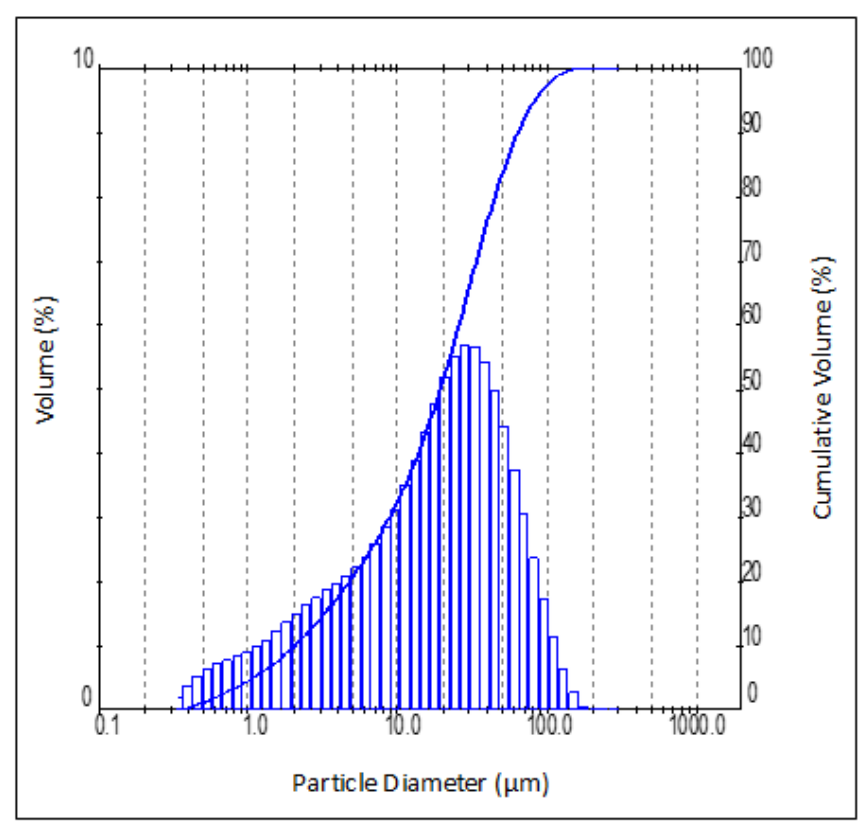

(a)

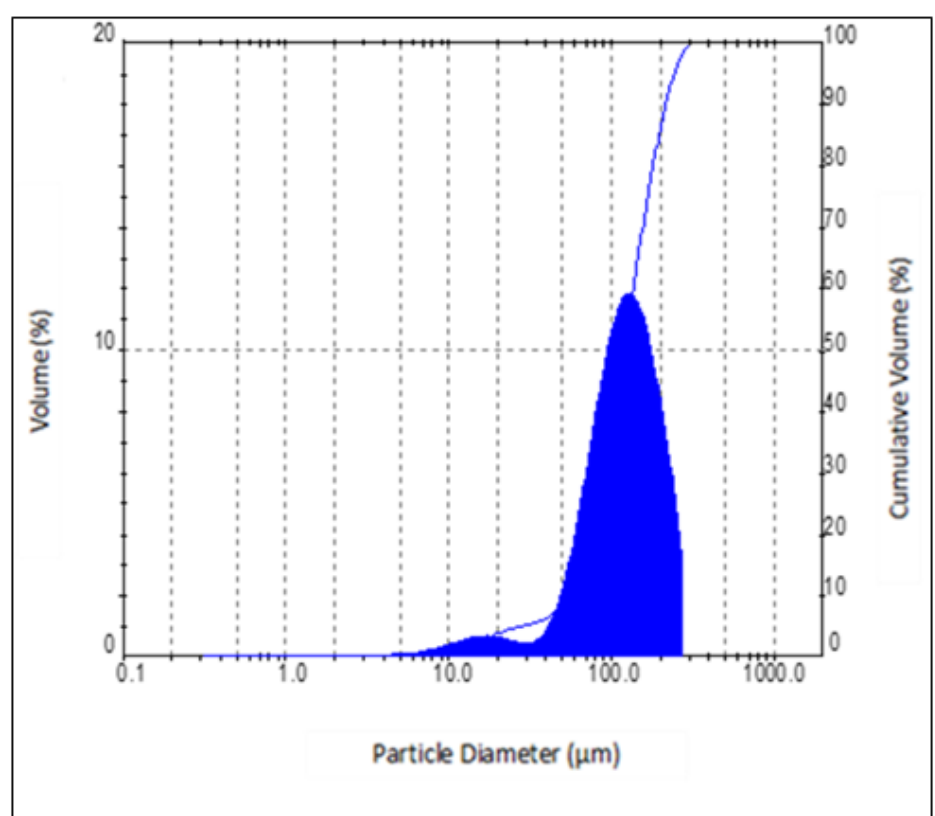

(b)

Figure 1

Particle size distribution of fly ash (a) and silica fume (b)

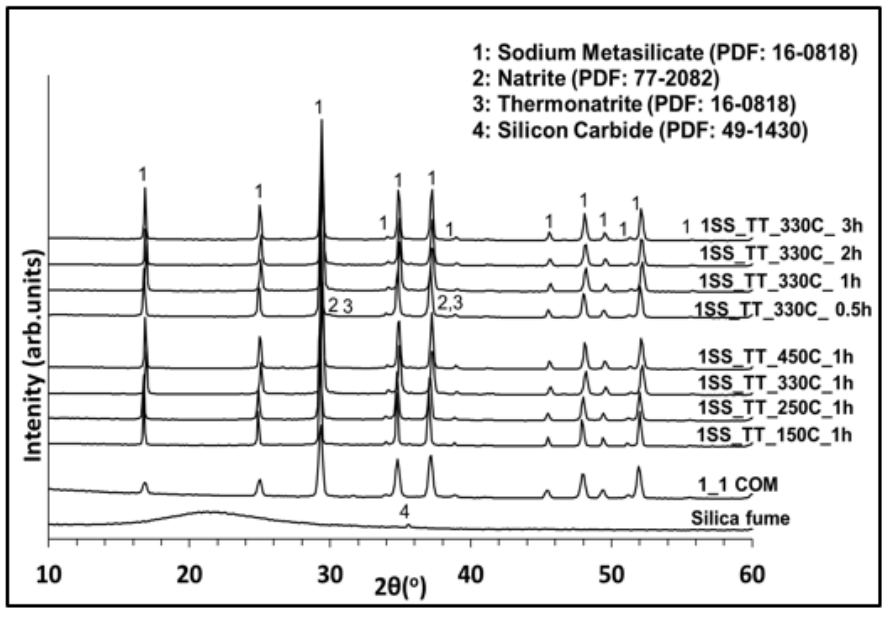

(a)

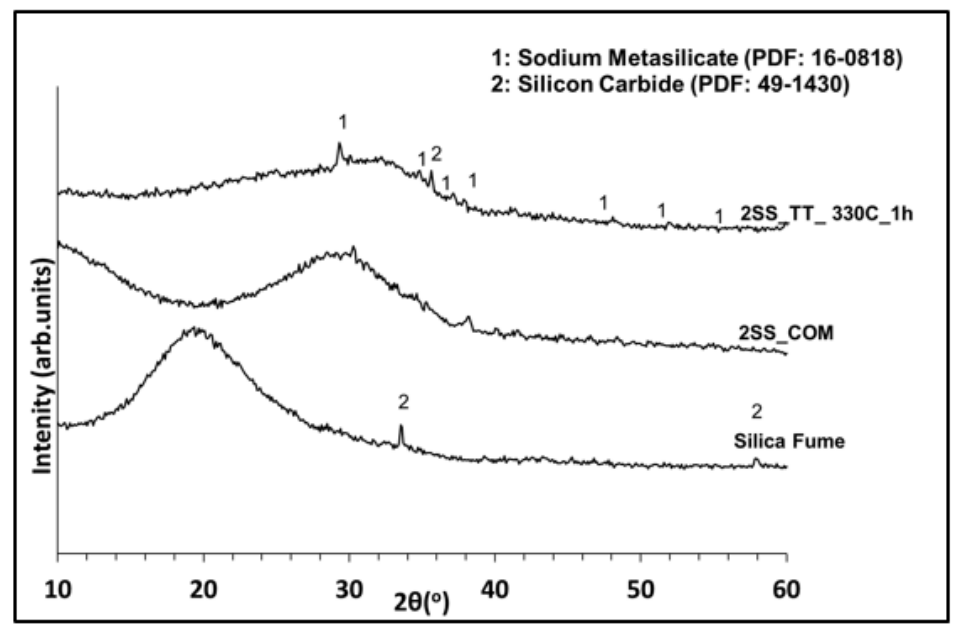

(b)

Figure 2

XRD patterns of SFAs prepared through thermal treatment with ratio $\mathrm{SiO}_{2} / \mathrm{Na}_{2} \mathrm{O}=1$ and 2 


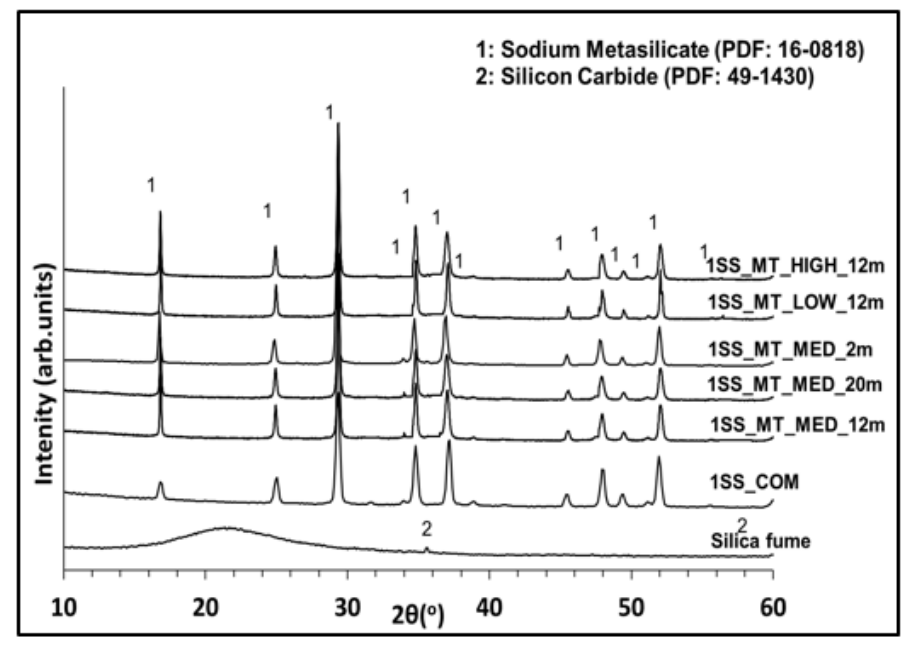

(a)

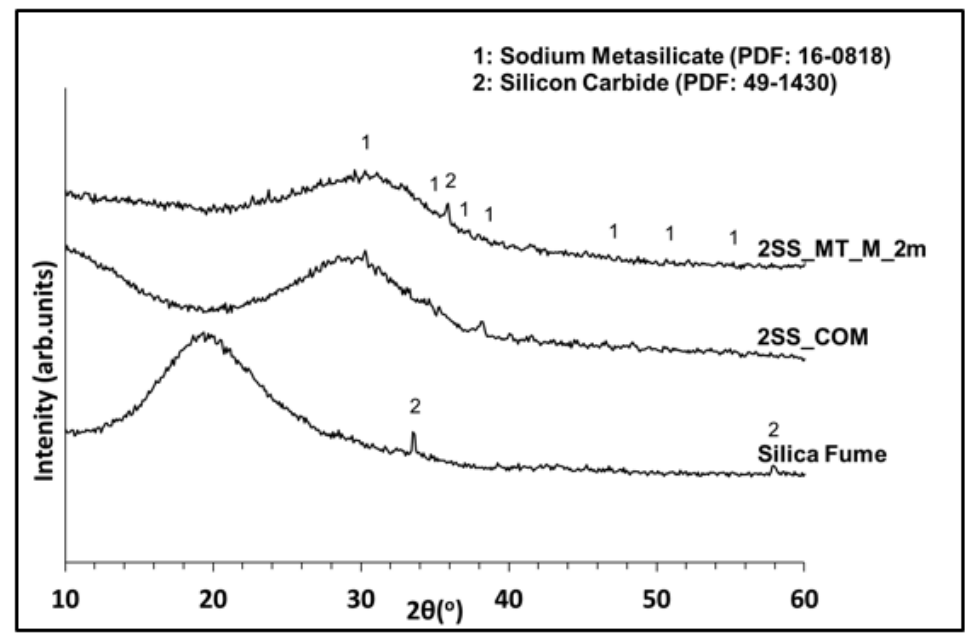

(b)

Figure 3

XRD patterns of SFAs prepared through microwave treatment with ratio $\mathrm{SiO}_{2} / \mathrm{Na}_{2} \mathrm{O}=1$ and 2

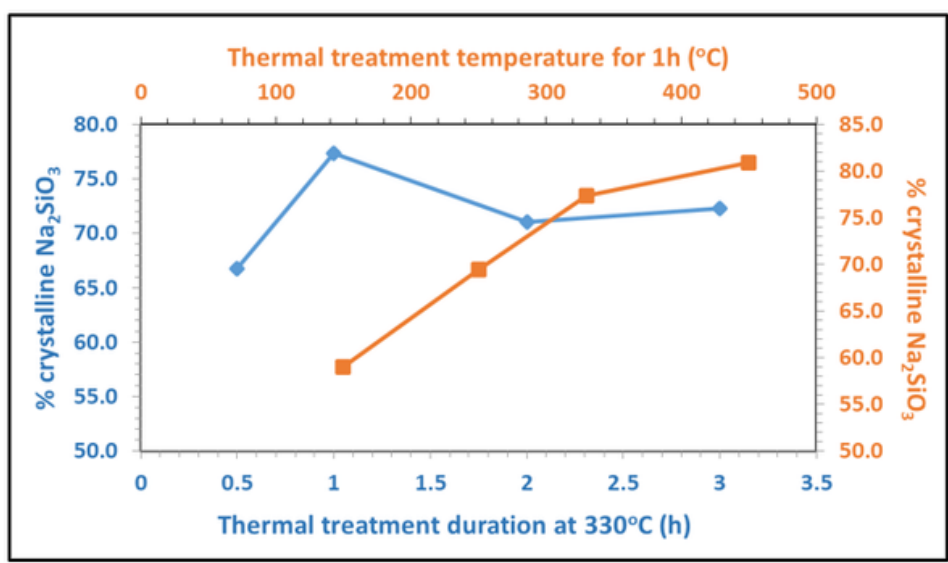

(a)

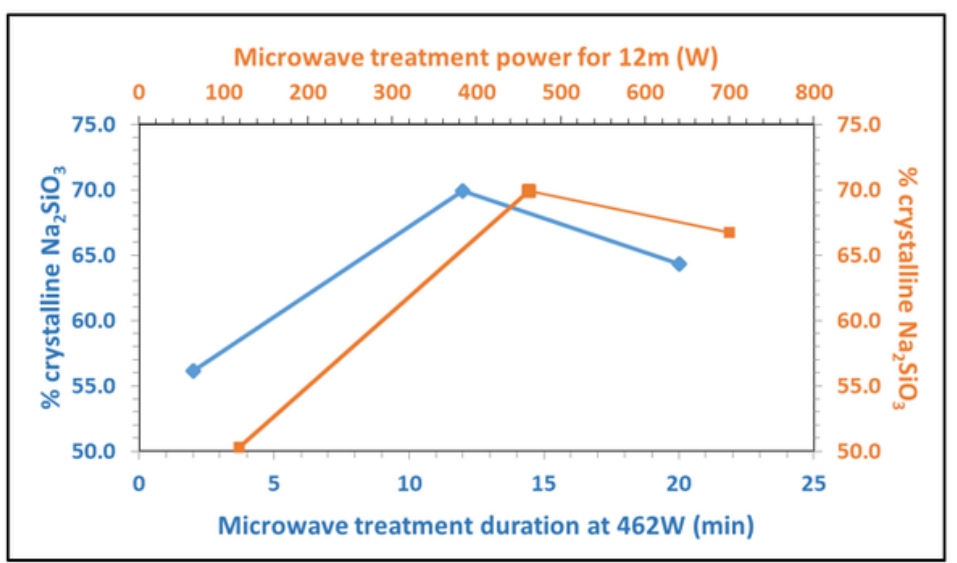

(b)

Figure 4

Effect of the examined parameters on the crystalline content of SFAs. 


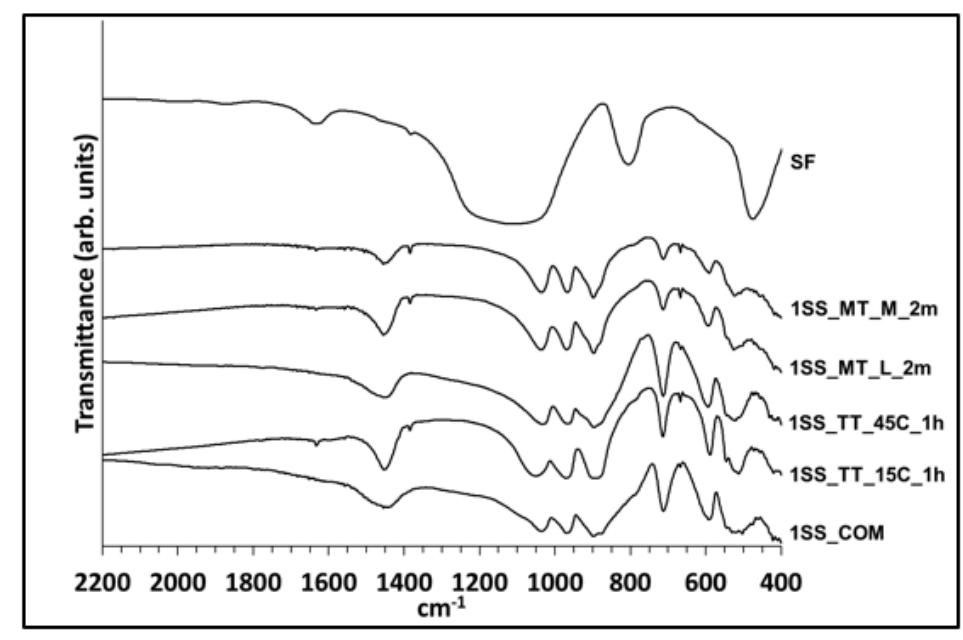

(a)

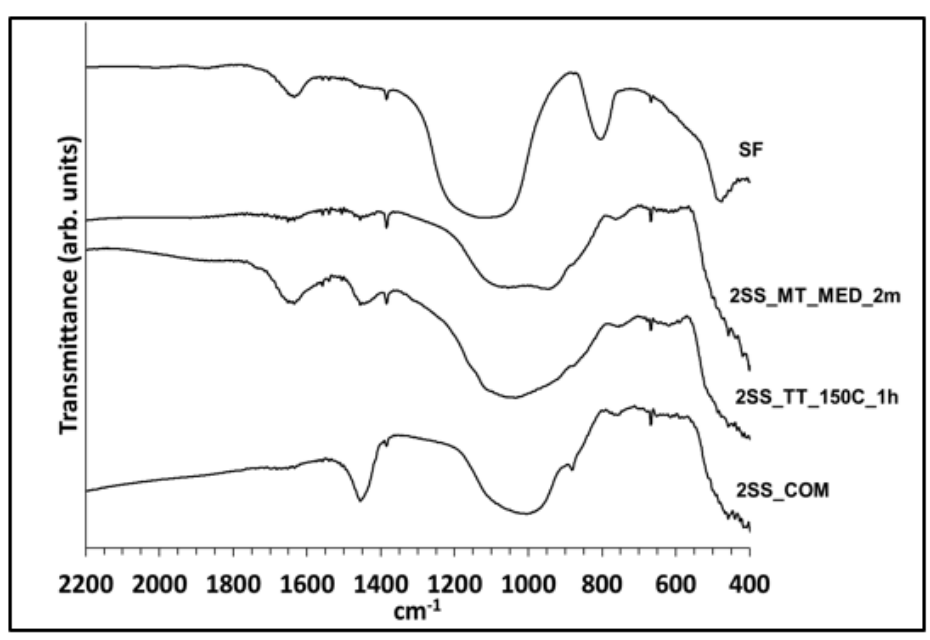

(b)

\section{Figure 5}

FTIR spectra of (a) SFAs with molar ratio $\mathrm{SiO}_{2} / \mathrm{Na}_{2} \mathrm{O}=1$ and (b) SFAs with molar ratio $\mathrm{SiO}_{2} / \mathrm{Na}_{2} \mathrm{O}=2$ along with those of commercial sodium silicate, silica fume

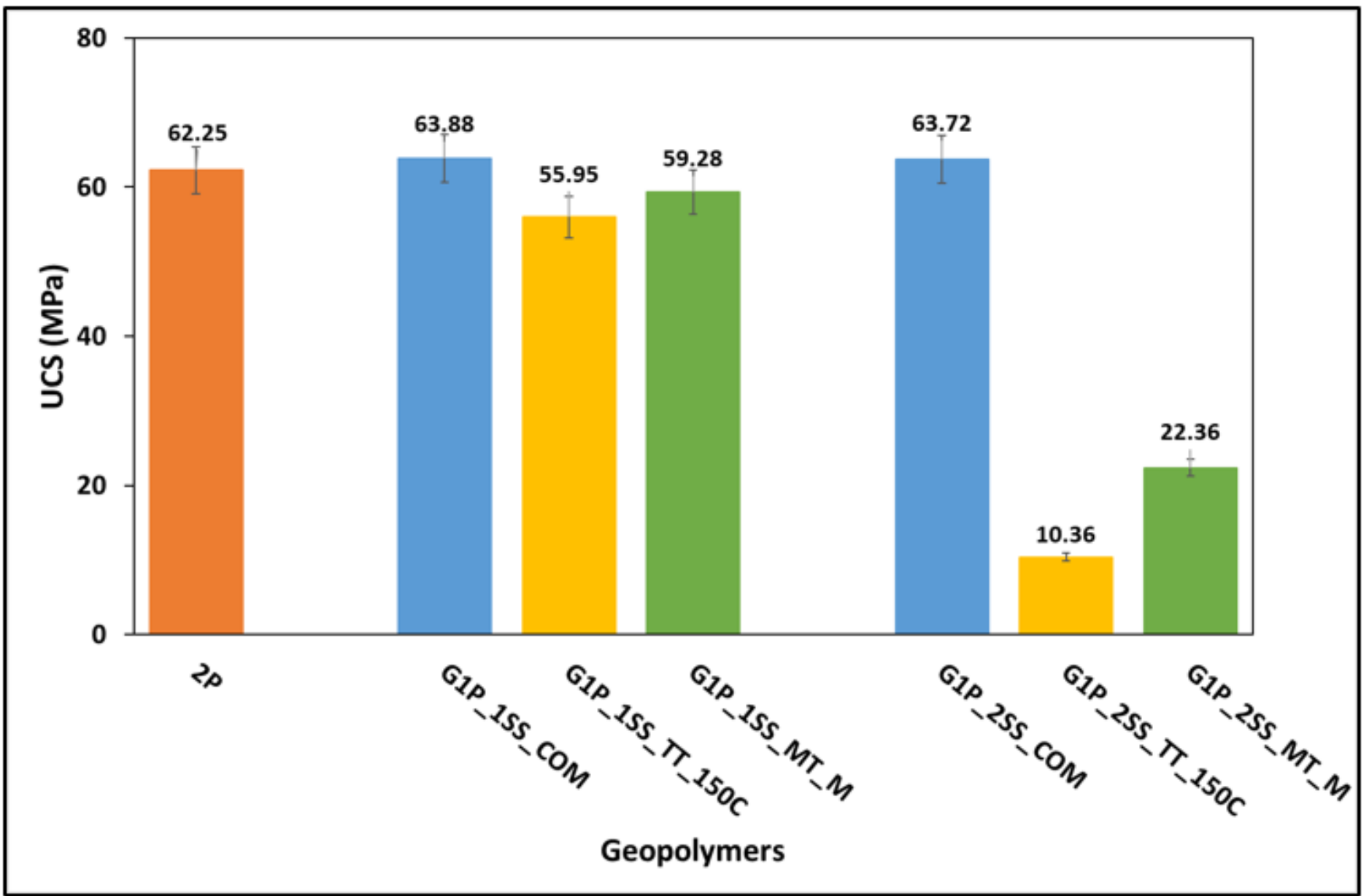

Figure 6

Compressive strength values of the prepared geopolymer specimens. 


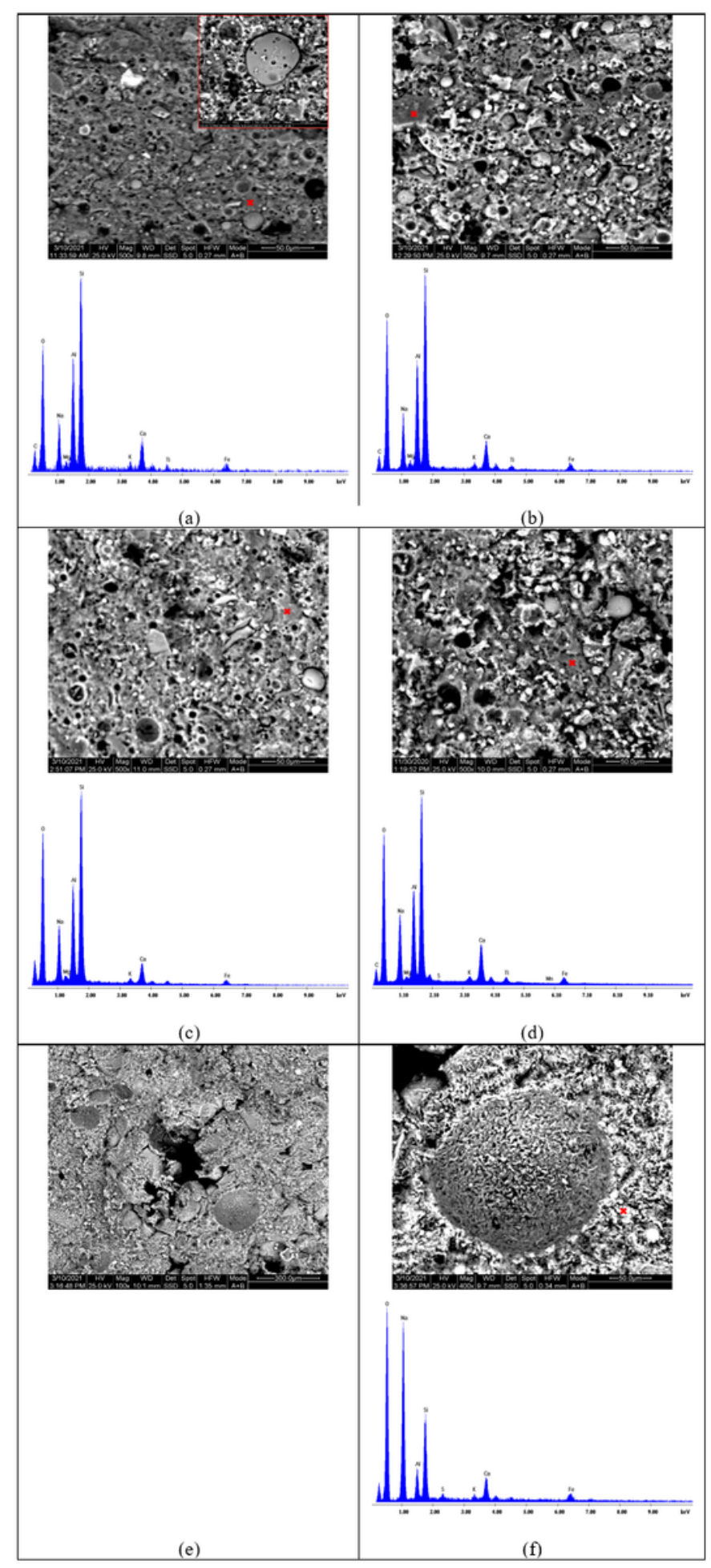

\section{Figure 7}

Backscattered micrographs of the prepared geopolymer samples: (a) G1P_1SS_COM, (b) G1P_1SS_TT_150C, (c) G1P_1SS_MT_M, (d) G1P_2SS_COM, (e) and (f) G1P_2SS_TT_150C along with their EDX analysis (the areas of analysis is marked with red signs in micrographs). 


\section{Supplementary Files}

This is a list of supplementary files associated with this preprint. Click to download.

- GraphicalAbstract.png 